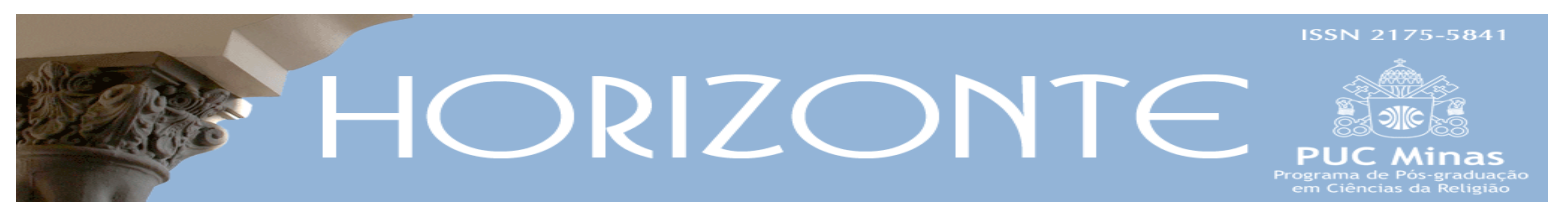

Dossiê: Teorias de linguagem e Estudos de Religião - Artigo Original (c)

DOI - 10.5752/P.2175-5841.2018v16n51p1085

\title{
Teorias da linguagem e estudos do discurso: apontamentos metodológicos para uma análise do discurso religioso
}

\author{
Theories of language and discourse studies: methodological notes for a \\ religious discourse analysis
}

Kenner Roger Cazotto Terra*

\begin{abstract}
Resumo
Sob o paradigma da Modernidade acreditava-se na referencialidade direta entre conceito e mundo, signos e realidade. Com os novos estudos linguísticos, a fissura e descontinuidade entre coisa e palavra revelaram a limitação das metanarrativas e suas derivações. A consequência natural desse horizonte foi uma verdadeira virada nas ciências humanas. A linguagem percebeu-se como significação e não reflexo direto das coisas a respeito das quais se pronuncia. Para os estudos da religião, essas renovadas perspectivas das teorias da linguagem serviram de mudança paradigmática, produzindo uma verdadeira explosão metodológica. Por isso, ferramentas habilidosas para os estudos da linguagem tem ganhado espaço nos estudos da religião, possibilitando compreendê-la como lócus de sentidos. Dessa forma, as múltiplas linguagens da religião, por vezes tratadas como distorção do real ou ideologia alienante, são acessadas como sistema complexo de narrativas, símbolos, ritos, artes e performances aptas para a criação e compreensão do mundo. A partir dessa preocupação, estabelecem-se as pesquisas das Linguagens da Religião cujos aportes teóricos e objetos avançam à produção simbólica da religião. Dentro dessa discussão metodológica, preocupada em compreender e interpretar as linguagens produzidas pela religião, 0 artigo pretende apresentar a Análise do Discurso traduzida para os estudos da religião e suas contribuições metodológicas aos estudos do discurso religioso. O texto apresentará, na primeira parte, os principais aportes teóricos da Análise do Discurso francesa. Essa tarefa apontará algumas intuições e provocações possibilitando uma Análise do Discurso Religioso.
\end{abstract}

Palavras-chaves: linguagens da religião; discurso religioso; enunciação; análise do discurso.

\begin{abstract}
Under the paradigm of Modernity, one believed in the direct referentiality between concept and world, signs and reality. With the new linguistic studies, the fissure and discontinuity between thing and word revealed the limitation of metanarratives and their derivations. The natural consequence of this horizon was a real turning point in the Human Sciences. The language was perceived not like direct reflection of the things, but like symbolic. For the studies of religion, these renewed perspectives on language theories served as paradigmatic change, producing a true methodological explosion. Thus methodologies for the language studies have been gaining ground in the studies of religion, making it possible to understand it as a locus of meaning. In this way, the multiple languages of religion, sometimes treated as real's distortion or alienating ideological, are accessed as a complex system of narratives, symbols, rites, arts and performances suitable for the creation and understanding of the World. From this concern, the researches of the Languages of Religion are established whose theoretical contributions and objects advance to the symbolic production of religion. Within this methodological discussion, concerned with understanding and interpreting the languages produced by religion, the article intends to present the Discourse Analysis translated for the studies of religion and its methodological contributions to the studies of religious discourse. The text will present, in the first part, the main theoretical contributions of the French Discourse Analysis. This task will point out some intuitions and provocations enabling a Religious Discourse Analysis.
\end{abstract}

Keywords: languages of religion; religious discourse; enunciation; discourse analysis.

Artigo submetido em 16 de agosto de 2018 e aprovado em 23 de outubro de 2018.

* Doutor em Ciências da Religião pela Universidade Metodista de São Paulo (UMESP). Professor na Faculdade Unida de Vitória (FUV). País de origem: Brasil. E-mail: krcroger@gmail.com 


\section{Introdução}

Desde a "linguistic turn" e a Filosofia Analítica, a partir do século XX, como crítica da linguagem, as Ciências Humanas tornaram a linguagem e seu poder de criação e compreensão da realidade lugar privilegiado de pesquisas, o que representa a gênese da "filosofia da linguagem". Se na Modernidade acreditava-se na referencialidade direta entre conceitos e mundo (signos e realidade), com os novos estudos linguísticos surge a denúncia a respeito da fissura e descontinuidade entre coisa e palavra, revelando-nos as limitações das metanarrativas e suas derivações. A consequência natural desse horizonte foi a diluição da afirmação, preservada desde Platão, da existência da realidade em si, uma essencialidade, e a linguagem como sua sombra ou representação linguística. De outro modo, tanto a "virada" quando a filosofia da linguagem colocaram as bases para a mudança epistemológica cuja principal afirmação é a não dissociação entre "mundo" e símbolos através dos quais o acessamos. Ou seja, a realidade não tem outro lugar de habitação senão na linguagem. Essa radical compreensão nega ser a linguagem simplesmente um meio pelo qual se expressam pensamentos pré-linguísticos: "linguagem como a constituição do próprio pensamento" (LAFONT, 1999, p. 3). Não há "um fora”, como se os signos fossem ato segundo. Pelo contrário, o contato com a realidade desde sempre se dá na linguagem estabelecida em sistemas múltiplos através dos quais desenvolvemos nossas relações semióticas.

Para os estudos da religião, especialmente no interesse pela relação entre linguagem e religião ou a própria religião como linguagem (NOGUEIRA, 2015, p. 7), essa mudança paradigmática tem se tornado uma explosão metodológica. Perspectivas reducionistas e positivistas, por tanto tempo reinantes, dão lugar para a possibilidade de compreensão da religião como espaço de sentidos. As linguagens da religião, desse modo, deixam de ser uma distorção do "real" ou ideologia alienante, como se essas fossem sempre obstáculos para o acesso direto e crítico à realidade - seja para legitimar opressão ou animar a esperança dos oprimidos. Pelo contrário, as expressões plurais da religião são percebidas, a partir dessas mudanças metodológicas, como sistema complexo de narrativas (mythos), 
símbolos, ritos, artes e performances etc. habilidosamente aptos para criação e compreensão de mundo. Ou seja, a religião, nessa perspectiva, torna-se estratégia textual no mundo da vida ${ }^{1}$ e construção simbólica da realidade. A partir dessa preocupação, estabelece-se a disciplina Linguagens da Religião cujos aportes teóricos e preocupações avançam para a produção simbólica da religião. Como explica Paulo Nogueira, ao traçar as fronteiras e problematização da área:

Nossa proposta é a de estudar aspectos mais elementares, e também mais fundamentais, da relação entre religião e linguagem. A pergunta inicial poderia ser: como ambas se relacionam entre si? Uma primeira resposta seria que a linguagem estrutura a religião. Essa proposta, no entanto, pode sugerir que existe a linguagem como suporte e a religião como âmbito de conteúdo. No entanto, não é assim se que experimenta religião na realidade. Ao assistirmos uma missa católica ou a um ritual de umbanda, por exemplo, somos conduzidos por tempo e espaço, por meio de códigos estruturados, sendo que dessa forma temos uma percepção de evento de linguagem e de experiência religiosa de forma concomitante. Talvez possamos subir um nível em nossa determinação linguística da religião ao dizer que qualquer experiência religiosa só pode ser tornada social por meio das convenções linguísticas. (NOGUEIRA, 2016, p. 243244).

As questões levantadas acima convergirão em acessar a religião - seguindo os horizontes de disciplinas como a Semiótica da Cultura - como sistema modalizante (MACHADO, 2003; NOGUEIRA, 2015, p. 102-123; LOTMANN, 2000), o qual modela a realidade por meio de sistemas linguísticos. De certa forma, a religião pode ser compreendida tanto como discurso por meio do qual se compreende o mundo quanto espaço dialógico e semiótico de formações discursivas. Por isso, entre tantas ferramentas auxiliares aos estudos das linguagens da religião as ciências do discurso, tradicionalmente conhecidas como Análise do Discurso $(\mathrm{AD})^{2}$, podem ser trazidas à baila. Por conseguinte, a $\mathrm{AD}$ está entre as disciplinas desenvolvidas no círculo das novas perspectivas das teorias da linguagem e o analista do discurso3, desse modo, é um profissional capaz de

\footnotetext{
${ }^{1}$ Mundo da vida aqui é compreendido não como a realidade rígida cujas ferramentas racionalistas tentam descortinar, mas corresponde à linguagem e ao reservatório cultural tratado como o lugar (lócus) no qual os sujeitos desenvolvem a interpretação de uma situação e ação compartilhada linguisticamente. Dessa forma, esse conceito é visto aqui a partir da Teoria da Ação Comunicativa, especialmente na perspectiva desenvolvida por J. Habermas (2002) (principalmente o capítulo "Acções, actos de fala, interacções lingüisticamente mediadas e o mundo vivo"); ver também: Habermas (2003).

2 Por vezes, na literatura, especialmente francófona, ensaia-se uma distinção entre "análise do discurso" e "análise de discurso", (CHARAUDEAU \& MAINGUENEAU, 2004, p. 45). Neste artigo seguiremos a expressão mais genérica, Análise do Discurso.

${ }^{3}$ Maingueneau (2017, p. III/16), em 7. Peut-on assigner des limites à l'analyse du discours?, diferencia linguística do discurso e análise do discurso, dizendo ser "la seconde n'étant qu'une des composantes de la premièr" (a segunda é só uma parte da primeira).
} 
articular saberes provenientes do campo no qual o discurso tem sido produzido com os conhecimentos elaborados pelas ciências da linguagem (ARNOUX, 2009, p. 13). A partir dessa proposição, o artigo pretende apresentar as bases conceituais da Análise do Discurso e suas contribuições para a interpretação dos discursos religiosos.

\section{A análise do discurso como disciplina do(s) discurso(s)}

A $\mathrm{AD}$ é identificada como um equivalente do estudo do discurso ou um conjunto de disciplinas cujo objeto é o "discurso". Sua origem não é facilmente identificável, porque não há um fundador, mas é resultado da convergência de correntes e disciplinas especialmente ligadas aos estudos do texto. Historicamente, a expressão "Análise do Discurso" vem do artigo Discurse Analyses: a Sample Text, escrito pelo linguísta americano Z. S Harris na década de cinquenta, no qual a identifica como ciência da estrutura do texto (MAZIÈRE, 2007, p. 7). Contudo, não é possível compreender o atual campo dos estudos do discurso sem levar em consideração a década de sessenta e as contribuições da etnografia da comunicação, da análise conversacional de inspiração etnometodológica da Escola francesa, do desenvolvimento das correntes pragmáticas, das teorias da enunciação e linguística textual (CHARAUDEAU; MAINGUENEAU, 2004, p. 43). Para a formação da disciplina, especialmente desenvolvida desde a França das décadas de 60 e 70, Maingueneau insiste que a origem da disciplina encontra-se na interação de certa tradição, da prática escolar e conjuntura intelectual (MAINGUENEAU, 1991, p.9). Nessa ordem, a primeira representaria o campo de pesquisas realizadas pela filologia dos textos; o segundo fator leva em consideração a preocupação na França, em espaços universitários e escolares, com a interpretação textual; e, por sua vez, a conjuntura intelectual da década de sessenta na França e na Europa marcada pela psicologia, marxismo althusseriano e a linguística, as quais viviam o rompimento com os estudos das palavras e abriam-se ao nível mais fraseológico, preparando o terreno para o estudo dos discursos (MAINGUENEAU, 1991, p. 10). Consequentemente, por sua interdisciplinaridade e multiplicidade de aplicações, os estudos do discurso apresentam-se com fronteira disciplinar instável. 
A Análise do discurso, situada no cruzamento das ciências humanas, é muito instável. Há analistas do discurso antes de tudo sociólogos, outros, sobretudo lingüistas (sic), outros antes de tudo psicólogos. A essas divisões acrescentam-se as divergências entre as múltiplas correntes [...]. Assistimos a uma descompartimentalização generalizada das pesquisas. Isso se deve à abertura de um diálogo entre as diferentes disciplinas que trabalham com o discurso e entre diversas correntes de análise do discurso. Pode-se, entretanto, distinguir alguns grandes polos: (1) os trabalhos que inscrevem o discurso no quatro de interação social; (2) os trabalhos que privilegiam o estudo dos gêneros de discurso; (3) os trabalhos que articulam os funcionamentos discursivos com as condições de produção de conhecimento ou os posicionamentos ideológicos; (4) os trabalhos que colocam em primeiro plano a organização textual ou a seleção de marcas de enunciação. (CHARAUDEAU; MAINGUENEAU, 2004, p. 45).

As muitas possibilidades de compreensão da tarefa da $\mathrm{AD}$ permitem estabelecer múltiplas metodologias de estudos do discurso, o que contribui para a instrumentalização de diversas ferramentas na análise das práticas discursivas. Seguindo a citação acima, para a opção (1), a AD se deteria às interações midiáticas, meios sociais de comunicação, suas estratégias de socialização de conteúdos, os mecanismos de manipulação etc. Para a opção (2), seguindo intuições bakhtinianas, os analistas dos discursos estariam atentos aos gêneros do cotidiano e suas vinculações sociais. Em relação ao (3), talvez uma das perspectivas mais comuns nos manuais brasileiros4, os quais encontram em M. Pêcheux (1990; 1988; 2008) e Foucault (2001) seus grandes representantes. Para este último horizonte de análise, o conceito althusseriano de ideologia e as relações com as formações discursivas são fundamentais, tornando o discurso materialização de perspectivas e formações ideológicas. Como consequência metodológica dessa perspectiva, surge a Análise Crítica do Discurso, que se detém às relações de poder entre os sexos, raças, classe social etc. (DIJK, 1993, p. 249-250). Por outro lado, o ponto (4) apresenta a prática da $\mathrm{AD}$ como instrumento de compreensão das estratégias de enunciação e o impacto do sujeito no texto, que é a linguagem em ação (FIORIN, 2008, p. 31). Essa perspectiva alcança às releituras e avanços da teoria linguística de Saussure, especialmente nas intuições de Benveniste (BENVENISTE, 1998). Para esse último grupo, a Análise do Discurso aplicada a textos tornou-se uma

\footnotetext{
${ }^{4}$ Alguns exemplos tradicionais através dos quais perceberemos isso com clareza são os manuais de Eni P. Orlandi (1999) e Helena H. Brandão (2006).
} 
prática comum5. Seguindo essa última perspectiva e levando em consideração os gêneros do discurso, a descrição de Maingueneau é esclarecedora:

Em minha opinião, o interesse que rege a análise do discurso é apreender o discurso como articulação de um texto e de um lugar social; ou seja, o objeto não é nem a organização textual ou a situação da comunicação, mas o que os liga através de um modo de enunciação. Pensar os lugares independentemente das palavras que eles permitem ou pensar as palavras independentemente dos lugares que fazem parte, seria aquém das exigências subjacentes à análise do discurso. A noção de "lugar social", no entanto, não deve ser entendida sociologicamente. Pode ser um posicionamento em um campo discursivo (política, religioso etc.). Em todos os casos, devemos destacar a centralidade da noção de gênero discursivo, que, como "instituição discursiva", anula qualquer exterioridade simples entre "texto" e "contexto". O sistema enunciativo é verbal e institucional. (MAINGUENEAU, 2017, p. III/16).

Maingueneau dá centralidade ao gênero discursivo e segue a perspectiva aberta pelos teóricos da enunciação. Como a atividade humana é necessariamente linguística por excelência, as formas e características nos seus usos são tão múltiplas quanto às atividades humanas. Contudo, não precisamos cair na radical aleatoriedade discursiva a ponto de não ser possível traçarmos formas e suas práticas identificáveis e comuns. Por outro lado, o conceito de gênero discursivo rompe/alarga com as tipologias textuais, por vezes chamadas de gênero textual. Se este pressupõe função e organização, aquele envolve condição de produção (SANT'ANNA, 2011, p.68). A clássica definição bakhtiniana esclarece a potência heurística do gênero do discurso e serve como componente importante para a AD:

O emprego da língua efetua-se em forma de enunciados (orais e escritos) concretos e únicos, proferidos pelos integrantes desse ou daquele campo da atividade humana. Esses enunciados refletem as condições específicas e as finalidades de cada referido campo não só por seu conteúdo (temático) e pelo estilo da linguagem, ou seja, pela seleção dos recursos lexicais, fraseológicos e gramaticais da língua mas, acima de tudo, por sua construção composicional. Todos esses três elementos - o conteúdo temático, o estilo, a construção composicional - estão indissoluvelmente ligados no todo do enunciado e são igualmente determinados pela especificidade de um determinado campo da comunicação. Evidentemente, cada enunciado particular é individual, mas cada campo de utilização da língua elabora seus tipos relativamente estáveis de

\footnotetext{
${ }^{5}$ Júlio Zabatiero (2007) é exemplo no Brasil dessa tentativa. Em seu manual de exegese ele aplica as teorias greimasianas, em diálogo como as teorias da ação comunicativa, para leitura dos textos bíblicos.
} 
enunciados, aos quais denominamos gêneros do discurso. (BAKHTIN, 2003, p. 261-262). ${ }^{6}$

Para o autor russo, o modo enunciativo da linguagem tem relativa estabilidade. Desta forma, a heterogeneidade dos discursos exigirá ao analista flexibilidade metodológica. Bakhtin (2003, p. 263) propõe a diferenciação entre gêneros discursivos primários (simples) e secundários (complexos): aqueles são as expressões do cotidiano, da comunicação discursiva imediata; enquanto estes surgem nas condições culturais mais organizadas, estáveis e desenvolvidas (romances, dramas, pesquisas científicas etc.). Contudo, Bakhtin não separa arbitrariamente essas duas formas de enunciado, mas afirma que no processo da formação dos discursos secundários eles incorporam e reelaboram diversos gêneros primários, que se formam nas condições de comunicação discursiva imediata, fazendo com que os gêneros primários percam, por integrarem os secundários, seu caráter imediato (BAKHTIN, 2003, p. 263). Na descrição do analista russo temos potencialidades e fragilidades, as quais foram discutidas no desenvolvimento da $\mathrm{AD}$. Como é perceptível, não se encontra nessa descrição uma diferenciação muito clara entre discurso, enunciado ou enunciação. Contudo, suas intuições a respeito do gênero do discurso servem indiscutivelmente para compreensão dos tipos relativamente estáveis do ato da língua tornar-se fala a fração da ação da linguagem e suas condições de enunciação. Ainda, mesmo que a diferenciação bakhtiniana entre enunciados simples e complexos não seja seguida à risca, suas lucubrações metodológicas abrem portas para compreendermos o lugar social dos enunciados (com suas interações intertextuais e interdiscursivas), o que será muito caro para a AD e auxiliará a Análise do Discurso Religioso.

Por essa razão, desde a década de sessenta, a $\mathrm{AD}$ tem feito dialogar suas diversas correntes e desenvolveu (definiu) métodos, separando-a como campo disciplinar autônomo e distinto das outras abordagens das quais se serve. Assim, "a totalidade dos enunciados de uma sociedade, apreendida na multiplicidade de seus gêneros, é convocada a se tornar objeto de estudo" (CHARAUDEAU; MAINGUENEAU, 2004, p. 46).

${ }^{6}$ Conferir também em Bakhtin (2016). 


\section{Do discurso}

Como qualquer conceito, "discurso" é alvo de diversos usos imprecisos. Por vezes, confundem-se discurso e fala discurso e texto ou discurso e língua, impedindo maior acuracidade terminológica e, por sua vez, metodológica. Como vimos, a Análise do Discurso é uma disciplina habilitada para nos ajudar na definição e estudos desse importante termo. Por isso, é preciso descrever, a partir desse campo disciplinar, o que significa "discurso", seu principal objeto. Somente assim será possível estendê-lo e interpretá-lo como parte da produção das linguagens da religião.

A $\mathrm{AD}$, como se percebeu na descrição de sua formação, rompe com as antigas perspectivas linguísticas e avança para as frases, enunciados e, por sua vez, prioriza as construções discursivas. Mesmo que seja devedora da linguística tradicional, seu desenvolvimento para o social e discursivo promove uma nova orientação nos estudos da fala e do texto.

Antes de qualquer coisa, discurso é um conjunto de enunciados organizados de maneira interacional e orgânica (DUCROT, 1984, p. 368-393). Dessa forma, o discurso (s) como objeto de análise é resultado de diversas perspectivas disciplinares. Em suma, podemos definir discurso como

[...] um fenômeno social complexo, multifacetado, que nasce a partir do diálogo entre discursos diversos. Constituiu-se no âmbito do já-dito e, ao mesmo tempo, é orientado para o discurso-resposta que é solicitado a surgir. Todo discurso responde a outros dizeres e, por conseguinte, é tecido heterogeneamente por uma diversidade de vozes (posições sociais, ponto de vista) mais ou menos aparentes. Entre o discurso e o objeto, entre o discurso e a personalidade do falante interpõe-se um meio flexível, muitas vezes difícil de ser penetrado, de discursos de outrem, de discursos alheios sobre o mesmo objeto, sobre o mesmo tema. O discurso, desse modo, configura-se a partir de um entrelaçamento de interações sociais complexas, pois em todos seus caminhos até o objeto, em todas as direções, o discurso se encontra com o discurso de outrem e não pode deixar de participar, com ele, de uma interação viva e tensa. Nesse processo, a materialização do discurso pressupõe a inscrição valorativa de um dado locutor, a posição de um sujeito frente a outros discursos. Em outras palavras, o discurso existe na forma de enunciados concretos de determinados falantes, sujeitos do discurso que se constituem dialógica e historicamente. Logo, o discurso é constitutivamente ideológico, dialógico e histórico. Os enunciados, segundo finalidades determinadas, 
interlocutores definidos, tempo e espaço próprios, concretizam-se em gêneros do discurso em esferas sociais de atividade humana. (FLORES et al, 2009, p. 84).

Nesse horizonte, o discurso revela-se como um fenômeno social e se estabelece na interatividade. Contudo, o social não seria simplesmente as classes ou o contexto histórico-social como as ciências mais racionalistas preveem, mas a teia de outros discursos, suas memórias culturais. O contexto é, na verdade, a interdiscursividade através da qual se alarga o alcance espaço-temporal do que seria o "fora” do texto. Consequentemente, não caímos no formalista radical ou no reducionismo historicista.

Além de dialógico e histórico, o discurso é fenômeno ideológico. Obviamente, o discurso, semioticamente, realiza ou materializa ideologias. Contudo, é preciso antecipar que ideologia para AD não é ocultação da realidade ou distorção da classe opressora para manter em claustro os grupos despossuídos. Ou seja, todo discurso representa ou veicula visão de mundo, revela imaginários, ideias e memórias de grupos através dos quais se pensa ou representa a realidade. Deixando de ser ideologia um tipo de “distorção da realidade”, podemos entendê-la linguística e discursivamente (HALL, 1996, p. 30). Stuart Hall, apreciando o conceito em horizontes discursivo e linguístico, defende que ideologia é uma estrutura mental - as linguagens, os conceitos, imagens do pensamento e os sistemas de representação - empregada por diferentes classes e grupos sociais para dar sentido, definir, figurar e dar inteligibilidade à maneira como a sociedade funciona (HALL, 1996, p. 26). Mesmo parecendo esquemática, essa ideia de ideologia, cara para a AD francesa, torna-se aqui uma proposta de "figuração" e não de "distorção", como as teorias marxistas defenderam. O discurso, nesse sentido, representa grupos e, uma vez inserido em formações ideológicas, preserva as concepções de mundo presentes em seus traços enunciativos ou metáforas de composição do texto.

Outra questão importante nessa discussão é a afirmação de que os discursos podem ser materializados em textualidades múltiplas. Para isso, urge a necessidade de conhecermos a distinção, basilar para a AD, entre texto e discurso. Para 
didaticamente se descrever o objeto da análise do discurso, abordar esses conceitos separadamente torna-se um caminho interessante - mesmo que na prática esses não sejam notavelmente separados, isso nos ajudará limitar suas fronteiras significativas.

Para Lótman e sua escola (LÓTMAN, 1996), o texto é um espaço semiótico de troca e diálogo no qual as línguas vivem a lógica da interação e interorganização em processos de modelização. Por sua vez, texto seria qualquer unidade de sentido. A grande contribuição dessa iniciativa para a pesquisa centra-se na compreensão da religião como um sistema de comunicação e elaboração de mensagens: "texto da religião" ou "texto cultural da religião" (NOGUEIRA, 2015, p. 16-17). Para a Semiótica Russa, o texto tem três funções: (1) função comunicativa; (2) função geradora de sentido; (3) função mnemônica (LÓTMAN, 2007). A primeira função foi a mais observada pelos linguistas durante muito tempo. Essa mostra o texto como processo de realização da língua natural. A função da linguagem seria transmitir a mensagem de um emissor ao receptor. A segunda função tem relação com o seu potencial polissêmico, o que proporciona a produção de novos textos no ato da comunicação de textos não mecânicos/manuais. A terceira função do texto é a mnemônica. Como bem diz Lótman, “o texto não é somente o gerador de novos significados, mas também um condensador de memória cultural. Um texto tem a capacidade de preservar a memória de seus contextos prévios" (LÓTMAN, 2007, p. 22). Os textos da cultura refletem esses encontros e trocas, os quais se processam a partir da tradução de tradições, que é feita criativamente, dando aos signos anteriores novos contornos que, por si, são cheios de possibilidades. A semiótica da cultura seria, nessa perspectiva, “(...) a disciplina que examina a interação de sistemas semióticos diversamente estruturados, a não uniformidade interna do espaço semiótico, a necessidade do poliglotismo cultural e semiótico" (LÓTMANN, 1996, p. 78). Por essa e outras razões, os textos sempre serão criativos e estratégicos na apropriação das memórias que os antecedem: 
nele e esquecer outros temporalmente ou por completo. (LÓTMAN, 1993, p. 19).

A noção de interatividade dos textos, unidades significativas como a Semiótica da Cultura defende, ajuda nas discussões sobre intertextualidade e interdiscursividade. Para Lótman, o texto não é fenômeno isolado, mas pertence a um grande sistema, chamado de semiosfera, que é o resultado e a condição para o desenvolvimento da cultura e fora da qual não pode haver linguagem e comunicação (LÓTMAN, 1990). A semiosfera pode ser definida, antes de qualquer coisa, a partir deste princípio: as coisas não existem isoladamente. Assim, a intertextualidade semiótica seria a maneira própria da textualidade. Contudo, para avançar enquanto caminho metodológico, a $\mathrm{AD}$ apresentará o (s) discurso (s) como conteúdo do texto e não os confunde.

Como discutimos acima, o conceito de texto para semiótica russa é largo e parece não fazer a distinção aqui desejada entre discurso o texto. Contudo, permite pensar a realidade linguística não isoladamente e ajuda-nos na defesa pelas teias texto-discurso na análise do sentido.

Tanto o texto quanto o discurso são, para a $\mathrm{AD}$, uma unidade inteira de sentido cuja organicidade é seu aspecto fundamental. No entanto, enquanto o texto é da ordem da manifestação, o discurso é da imanência. Isso não significa que aquele seja mais simples ou superficial e este, o discurso, profundo e importante. Mas, simplesmente, “a manifestação é a presentificação da forma numa substância, o que significa que o discurso é o plano do conteúdo, enquanto o texto é o plano da expressão. O texto é manifestação do discurso" (FIORIN, 2012, p. 148). Por isso, como anterior ao texto, os discursos do mesmo campo de significação e compreensão de mundo podem ser presentificados em textos diferentes. À luz das teorias da enunciação, os dois são produtos enunciativos, mas diferem quanto ao modo de existência semiótica, porque discurso é atualização das virtualidades da língua e do universo discursivo, já o texto é a realização do discurso por meio da manifestação (FIORIN, 2012, p. 148). Dessa forma, por ser o texto unidade de 
sentido em contínua interação no espaço da cultura e o discurso fenômeno dialógico, podemos falar em interdiscursividade e intertextualidade.

Bakhtin, também para essa discussão, é muito importante. Contudo, precisamos esclarecer que não há em qualquer lugar nas suas obras a expressão "intertextualidade", pois "na obra bakhtiniana não ocorrem os termos interdiscurso, intertexto, interdiscursivo, interdiscursividade, intertextualidade" (FIORIN, 2006, p. 162) 7. O mais preciso seria indicar a paternidade bakhtiniana para o termo "dialogismo", segundo o qual "todo enunciado é dialógico" (BAKHTIN, 1986, p. 274). Na leitura de Bakhtin, não diferenciando discurso de texto - em sua obra, enunciado, texto e discurso ora são tratados como equivalentes, ora não fica nítida a questão da intertextualidade porque um texto estará sempre em diálogo com outros textos e sempre será um diálogo de várias escrituras. Contudo, mesmos seguindo e interpretando às intuições embrionárias do teórico russo, especialmente sua discussão sobre diálogo entre os enunciados, é possível criar fronteiras metodológicas entre interdiscursividade e intertextualidade.

$\mathrm{O}$ termo intertextualidade fica reservado apenas para os casos em que a relação discursiva é materializada em textos. Isso significa que a intertextualidade pressupõe sempre uma interdiscursividade, mas que o contrário não é verdadeiro. Por exemplo, quando a relação dialógica não se manifesta no texto, temos interdiscursividade, mas não intertextualidade. No entanto, é preciso verificar que nem todas as relações dialógicas mostradas no texto devem ser consideradas intertextuais. (FIORIN, 2006, p. 181).

$\mathrm{Na}$ interdiscursividade, discursos (que seriam os enunciados em Bakhtin) estão em diálogo com outros discursos - entre perspectivas em termos de conteúdo e compreensão de mundo -, o que revela tensão e diálogo entre possíveis lugares de compreensão da realidade. Por sua vez, a intertextualidade - em epígrafe, citação, referência, paráfrase, paródia, pastiche e outros tipos de interação - refere-

\footnotetext{
${ }^{7}$ Inclusive, no prefácio da obra Problemas da poética de Dostoiévski, Paulo Bezerra critica duramente a respeito da identificação desse termo com Bakhtin a partir de sua tradução: "No Brasil, essa 'adaptação' vem contribuindo para a deformação do pensamento bakhtiniano em escala temível. Citemos ao menos um exemplo. No livro Intertextualidades, de G. Paulino, I. Walty e M. Z. Curry, lemos: 'a intertextualidade foi estudada primeiramente pelo pensador russo Mikhail Bakhtin' (PAULINO; WALTY; CURRY, 1995, p. 21). E as autoras citam minha tradução de PPD [Problemas da poética de Dostoiévski] como fonte bibliográfica. Em que página do livro aparece o termo "intertextualidade", caríssimas caras-pálidas, que eu, o tradutor, nunca o encontrei?" (BEZERRA, 2011, p. XX-XXI).
} 
se à relação entre textos/manifestações linguísticas. Na prática, quase não conseguimos fazer essa clara delimitação, mas para a $\mathrm{AD}$ essa fronteira permite análises mais delimitadas e específicas às formações discursivas. Assim, levando em consideração o texto como unidade de sentido na cultura, sempre estará em diálogo com outros textos. Esses, por sua vez, serão manifestações de discursos com potências interdiscursivas.

\section{Da enunciação}

A AD pode ser identificada, a partir da taxonomia apresentada até aqui, como ciência do enunciado cujo objeto é o ato da língua torna-se linguagem, ou seguindo Saussure, da langue para parole. Antes de qualquer coisa, enunciação é o ato produtor do enunciado, a utilização da língua (BENVENISTE, 1998). Seguindo a ideia discursiva de enunciação, essa é um acontecimento contextualizado e apreendido na multiplicidade de suas dimensões social e psicológica (CHARAUDEAU; MAINGUENEAU, 2004, p. 193). Se para a linguística tradicional a enunciação é o funcionamento individual da língua, para a $\mathrm{AD}$ ela é fundamentalmente interdiscursiva: "a enunciação equivale a colocar fronteiras entre o que é selecionado e, pouco a pouco, tornado preciso (através do que se constituiu o 'universos de discurso') e o que é rejeitado" (CHARAUDEAU; MAINGUENEAU, 2004, p. 195). Alguns pressupostos precisam ser identificados a respeito da enunciação:

I. Não é uma ação simplesmente individual ou subjetivamente livre, mas pressupõe a interdiscursividade da linguagem;

II. A enunciação é ato criativo e não tem referencialidade direta com a realidade, mas transborda e ficcionaliza o mundo;

III. Os enunciados, resultado dos atos enunciativos, são também narrativização de memórias em procedimentos parafrástico ou/e polissêmico: este como ruptura e deslocamento; aquele como o permanente ou o mesmo em formas diferentes (ORLANDI, 1999, p. 36-37). Assim, o contexto imediato do discurso não é somente o social ou histórico, mas o "já dito", das memórias, imaginários 
produzidos em redes sempre complexas e imprevisíveis de sentido. Por isso, o parafrástico e o polissêmico permitem a preservação e rompimento, ressignificação e estabelecimento, abertura e fechamento semióticos, tradução e releitura;

IV. O ato de enunciação deixa marcas no enunciado de suas estratégias estéticas e pragmáticas: o sujeito/narrador/emissor/autor implícito interage com os signos do texto e nele deixa indícios de ação;

V. O discurso, por sua vez, seria o conjunto de enunciados, os quais se estruturam em dinâmicas semióticas na cultura e em intersecção textual.

O conceito de memória de Jan Assmann, Aleida Assmann e Iuri Lótman segue caminhos epistemológicos parecidos com o que podemos chamar de "já dito" na $\mathrm{AD}$. Tanto para $\mathrm{AD}$ quanto para os teóricos citados, a memória é um fenômeno da cultura, resultado de interação, discursivizada e coletiva. Talvez, esta última característica seja uma das mais importantes para nossos interesses de analisar o discurso a partir de suas estratégias parafrásticas e polissémicas. Contudo, é preciso deixar claro a não linearidade ou repetição direta no processo parafrástico, no qual o "já dito" é resultado de relações de sentido e mediações. Para Lótman, memória comum (memória da cultura) refere-se a textos que circulam no quadro sincrônico da cultura, como também potencializa a geração de novos textos (LÓTMAN, 1996). Surge desses autores, na esteira de Maurice Halbwachs, que abriu as portas para o mundo coletivo das memórias (RICOEUR, 2007; SANTOS, 2003; ERLL; NÜNNING, 2008; ERLL, 2011), a perspectiva da memória cultural, possibilitando tratá-la como sistema semiótico e conjunto de textos perenizados.

É assim que podemos considerar a memória cultural, como um caso especial da memória comunicativa. Tem outra estrutura temporal: se pensamos em um típico ciclo trigeneracional da memória comunicativa com um espaço sincrônico, a memória cultural, com suas tradições que podem ser rastreadas até um passado distante, conforma-se a um eixo diacrônico. (ASSMANN, 2008, p. 25).

Na memória cultural a relação do simbólico com a recordação é sempre contínua e aberta à possibilidade de utilizações políticas. Da mesma maneira, a memória cultural permite ao indivíduo se orientar pelos espaços da recordação (ASSMANN, 2011). 
Como a consciência, a linguagem e a personalidade, a memória é um fenômeno social, e na medida em que recordamos, não só descemos às profundezas de nossa vida interior mais própria, mas introduzimos nesta vida (interior) uma ordem e uma estrutura que estão socialmente condicionadas e que nos ligam ao mundo. Toda consciência está mediada pelo social. (ASSMANN, 2008, p. 18).

Por isso, as mais íntimas memórias têm seus vínculos sociais, seja na dinâmica da transmissão, porque é interação, ou mesmo no que precede sua transmissão, a recordação. Fala-se, portanto, de ordenação daquilo que nossas funções neurais preservaram. Lembrar é, nesse sentido, organizar e não resgatar o passado: "nenhuma memória pode preservar o passado" (ASSMANN, 1995, p. 130).

Dessa forma, se pretendemos defender as estratégias de enunciação como narrativização parafrástica e polissêmica das memórias, o discurso seria o lugar privilegiado para análise e interpretação dessas estratégias. Além disso, a discursivização das memórias presentes no conjunto de atos enunciativos é a possibilidade de construção de identidade, compreensão de mundo e articulação da realidade, que não é, segundo as teorias da linguagem, somente um objeto para o sistema de símbolos, mas existe somente nele.

\section{Por uma análise do discurso religioso}

Depois desse arrazoado conceitual, torna-se possível apontar para provisórias intuições metodológicas. Não é possível dar forma manualística a esta parte. Contudo, arriscar-se-á indicar caminhos de análise dos discursos da religião. Por isso, como instrumento, a $\mathrm{AD}$ pode contribuir significadamente com as Ciências da Religião.

Entre outras coisas, os discursos da religião são propostas de compreensão e significação do mundo. Neles encontramos, para além da realidade "bruta", a mediação da linguagem religiosa. Por isso, a religião seria "texto" e "expressão" das manifestações de significação. E, levando em consideração a sua multiplicidade de expressões, dificilmente podemos falar em "discurso religioso", no singular, porque induz ao reducionismo monofônico, pois cada expressão religiosa, como objeto de averiguação da construção de sentido, carrega diversidades discursivas. 
Por vezes, tentou-se definir os traços comuns do discurso da religião, como se houvesse um tipo-ideal discursivo religioso. Orlandi (1996, p. 154) é um exemplo dessa redução pouco favorável para esse campo de estudos. A pesquisadora usa o termo "reversibilidade" intentando traçar as tipologias discursivas, dividindo-as em discurso lúdico, discurso polêmico e discurso autoritário. Segundo essa estruturação, se a reversibilidade é a troca de papeis entre locutor e ouvinte, a pouca mudança de lugares e o pequeno espaço para a polissemia, comum ao lúdico, torna o discurso religioso, nessa tipologia, autoritário (ORLANDI, 1996, p. 131). Para a autora, há um desnivelamento e assimetria na relação entre o locutor e o ouvinte. Para Orlandi, no discurso religioso Deus está em plano espiritual e o ouvinte no temporal. As duas ordens de mundo são totalmente diferentes para os sujeitos, e essa ordem é afetada por uma forte expressão hierárquica, desigualdade e desnivelamento. Dessa forma, o locutor é imortal, eterno, onipotente, onipresente, onisciente e todo poderoso, enquanto os seres humanos, os ouvintes, são mortais e efêmeros (ORLANDI, 1996). Para essa perspectiva, a voz que se fala no discurso religioso em seus representantes (padre, pastor, profeta) se dá em forma de relação simbólica. Sob as bases formais da relação direta com a autoridade, essa voz, que não é modelável ou modificável, é regida por regras e regulamentos. Por isso, Orlandi acaba definindo rapidamente que o sentido do discurso religioso é monossêmico (ou pretende ser) (ORLANDI, 1996, p. 246). Mesmo que a tentativa seja respeitável, a análise torna-se extremamente reducionista e limitada, porque não percebe as multiplicidades discursivas das linguagens da religião e impede maior aplicabilidade das diversas ferramentas dispostas por esse campo disciplinar. Consequentemente, perspectivas como essa podem gerar conclusões heuristicamente frágeis, levando a firmações simplistas como esta: "o discurso religioso é aquele que faz ouvir a voz de Deus ou de seus enviados (profeta, pastor, padre)" (Orlandi, 1996). Logo na primeira avalição dessa forma de acesso, percebe-se que o conceito "religião" pressuposto no tipo-ideal “discurso religioso" é monoteísta e judaico-cristão. Os estudos das linguagens da religião, em diálogo com o referencial metodológico da $\mathrm{AD}$, não podem cair em reducionismos dessa estirpe. Pelo contrário, devem se abrir para a religião como 
um texto da cultura no qual há construções de sentidos, intertextualidades e intertextualidades múltiplas, como múltiplos são os gêneros discursivos.

A experiência do sagrado produz conjuntos complexos de expressões, as quais instrumentalizarão diversas materialidades textuais da cultura. Discursos proféticos, apocalípticos, parentéticos, místicos etc. poderão ser identificados e avaliados a partir de seus usos e releituras. Por outro lado, as marcas enunciativas dos discursos religiosos podem ser avaliadas e, se possível, compreendidas à luz de suas estratégias significativas expostas na enunciação, as quais mostrarão a construção de temporalidades, os instrumentos dêiticos das expressões religiosas e suas manifestações em diversas materialidades.

Os discursos religiosos manifestos em ritos, mitos, na cultura material, em símbolos e etc. poderão ser avaliados nas relações interativas e percebidos a partir das construções dialógicas. Até mesmo o conceito de contexto, nessa perspectiva, pode ser alargado e a análise do discurso das linguagens da religião perceberá o "extra" ou o "histórico" como a teia semiótica de discursos e textos da cultura. Então, mesmo que identifiquemos marcas características do discurso religioso, enrijecê-lo a um tipo-ideal não ajudará nas pesquisas.

Por fim, como ferramenta de análise, podemos listas algumas intuições e horizontes práticos do uso da Análise do Discurso Religioso.

a. A leitura dos textos sagrados da religião pode ser realizada, dessa forma, seguindo a identificação do percurso gerativo do sentido (GREIMAS, 1989). Por isso, as escrituras religiosas (incluído as orais) serão tratadas a partir de outros textos e discursos, dentro de um sistema dialógico. Por sua vez, os textos das religiões serão acessados como materialização de memórias e resultado de processos parafrágicos e polissêmicos. A distinção entre texto e discurso ajudaria na compreensão das obras judaico-cristãs, por exemplo, torná-las mecanismos de veiculação de compreensão de mundo das comunidades discursivas, o que romperia com leituras historicistas. 
b. A partir da Análise do Discurso Religioso as expressões da religião são vistas como lugares discursivos, o que privilegiaria as relações dialógicas. E, seguindo essa proposta, como texto da cultura, as experiências religiosas não são ecos de dominação ou simplesmente fatos sociais (funcionais ou alienantes). Pelo contrário, elas tornam-se discursivização da realidade, articulada através de gêneros discursivos, dentro de relações de tradução e interpretação de outros discursos. Para os estudos relacionados à religiosidade brasileira, por exemplo, os grupos religiosos seriam catalogados a partir de seus traços enunciativos, seus hibridismos discursivos e à luz da utilização de gêneros do discurso. Além disso, as expressões contemporâneas seriam avaliadas em seus lugares sociais de formação discursiva e seus sujeitos tratados como agentes de construção discursiva de identidade. Por exemplo, o que seria (m) o(s) Pentecostalismo (s) a partir desse horizonte? Categorias como neopentecostal, Pentecostalismo Clássico etc. seriam ainda possíveis? E as relações intertextuais e interdiscursivas como as diferentes matrizes religiosas? Quais as implicações para os estudos da religião "popular” e da “elite”, no Mundo Antigo ou nas regiões periféricas brasileiras, sob a égide das relações dialógicas dos discursos? Ou melhor, o que seria religião "popular” e da “elite” se levarmos em consideração a perspectiva dialógica dos discursos?

c. Ritos, mitos, performance, expressões artísticas, iconografias, músicas, mídia, xilogravuras e quaisquer expressões das linguagens da religião tornam-se, assim, enunciações através das quais podemos avaliar o conjunto do dito e não dito, sua forma de significação, recepções de memórias e construções discursivas. Consequentemente, se Linguagens da Religião é prevista como campo disciplinar, a Análise do Discurso Religioso torna-se instrumento eficaz para compreensão dos discursos da religião, desde suas estratégias enunciativas às relações dialógicas na cultura. 


\section{Conclusão}

É possível afirmar, com as reservas necessárias, que os estudos da religião têm vivido mudanças interessantes. Se por um lado falamos em "virada linguística” nas teorias da linguagem, cuja mais importante afirmação gira em torno das relações entre linguagem e realidade, significação e referencialidade, para os estudos dos fenômenos religiosos o impacto também já pode ser percebido. As pesquisas sociológicas e históricas contribuíram para a afirmação da área, mas com as provocações vindas das teorias da linguagem a pergunta pela relação entre religião e linguagem tem ganhado muita força. A própria religião, afirma Nogueira (2015, p.7), estabelece-se como uma forma de linguagem, com múltiplas manifestações significativas.

Essas preocupações produzem novas perguntas e exigem renovação de instrumentalização para a pesquisa. Para isso, muitas ferramentas surgem com potencial heurístico. Entre elas podemos elencar a não muito antiga e flexível Análise do Discurso. Essa, como resultado do encontro de grandes campos disciplinares (interdisciplinar por natureza), disponibiliza instrumentos e conceitos aptos ao estudo do discurso.

Bakhtin, um dos importantes autores lidos pelos analistas do discurso, dirá que o discurso é a língua em sua integridade concreta e viva e não a língua como objeto específico da linguística, obtido por meio de uma abstração absolutamente necessária de alguns aspectos da vida concreta do discurso (BAKHTIN, 2008, p. 207). Esse objeto como fonte da linguagem tem na Análise do Discurso um espaço privilegiado de estudos. Nela conjugam diversos conceitos e perspectivas, todos ligados, de uma forma ou de outra, aos estudos linguísticos, preocupados com os estudos discursivos. Neste ensaio, foram apresentadas possíveis contribuições dessa disciplina para os estudos do fenômeno religioso, o que pode nos abrir outros caminhos metodológicos, os quais auxiliem nos estudos dos discursos produzidos pela religião. 


\section{REFERÊNCIAS}

ARNOUX, ELVIRA N. Análisis del discurso. Modos de abordar materiales de arquivo. 2. ed. Buenos Aires: Santiago Arcos Editor, 2009.

ASSMANN, Aleida. Espaços da recordação: formas e transformações da memória cultural. Campinas: Unicamp, 2011.

ASSMANN, Jan. Collective memory and cultural identity. New German Critique, n. 65, p. 130-150, 1995 .

ASSMANN, Jan. Religión y memoria cultural. Buenos Aires: Lilmod, 2008.

BAKHTIN, Mikhail Mikhailovich. Estética da criação verbal. Introdução e tradução de Paulo Bezerra; prefácio à edição francesa de Tzvetan Todorov. 4. ed. São Paulo: Martins Fontes, 2003.

BAKHTIN, Mikhail Mikhailovich. Marxismo e filosofia da linguagem: problemas fundamentais do método sociológico na ciência da linguagem. 3. ed. São Paulo: Hucitec, 1986.

BAKHTIN, Mikhail Mikhailovich. Os gêneros do discurso. São Paulo: Editora 34, 2016.

BAKHTIN, Mikhail Mikhailovich. Problemas da poética de Dostoiévski. Tradução Paulo Bezerra. 4. ed. Rio de Janeiro: Forense Universitária, 2008.

BENVENISTE, E. Problemas de linguística geral I. Campinas: Pontes, 1998.

BEZERRA, P. Prefácio: Uma obra à prova do tempo. In: BAKHTIN, M. Problemas da poética de Dostoiévski. Tradução Paulo Bezerra. Rio de Janeiro: Forense Universitária, 2011.

BRANDÃO, Helena H. N. Introdução à análise do discurso. Campinas: Unicamp, 2006.

CHARAUDEAU, P.; MAINGUENEAU, D. Dicionário de análise do discurso. São Paulo: Contexto, 2004.

DIJK, Teun A. Van. Principles of critical discourse analysis. Discourse \& Society, London, v. 4, n. 2, p. 249- 283, 1993.

DUCROT, Oswald. Enciclopédia einaudi. Linguagem - enunciação. Lisboa: Imprensa Nacional, 1984. v. 2.

ERLL, Astrid. Memory and culture. New York: Palgrave Macmillan, 2011.

ERLL, Astrid; NÜNNING, Ansgar (Ed.). Cultural memory studies: an international and interdisciplinary handbook. Berlin; New York: Walter de Gruyter, 2008. 
FIORIN, José Luiz. As astúcias da enunciação. As categorias de pessoa, espaço e tempo. São Paulo: Ática, 2008.

FIORIN, José Luiz. Interdiscursividade e intertextualidade. In: BRAIT, Beth (Org.). Bakhtin: outros conceitos-chave. São Paulo: Contexto, 2006. p. 161-193.

FIORIN, José. Luiz. Da necessidade da distinção entre texto e discurso. In: BRAIT, BETH; SOUZA-E-SILVA, Maria. Cecília. (Org.). Texto ou discurso. São Paulo: Contexto, 2012. p. 146-165.

FLORES, Valdir do Nascimento et al. Dicionário de linguística da enunciação. São Paulo: 2009.

FOUCAUlT, Michel. A ordem do discurso. 7. ed. São Paulo: Edições Loyola, 2001.

GREIMAS, Algirdas Julien; COURTÉS, Joseph. Dicionário de semiótica. São Paulo: Cultrix, 1989.

HABERMAS, J. Racionalidade e comunicação. Lisboa: Edições 70, 2002.

HABERMAS, J. Teoría da acción comunicativa II: crítica de la razón funcionalista. 4. ed. Madri: Taurus, 2003.

HALL, Stuart. The problem of ideology: Marxism without Guarantees. In: DAVID, Morley; CHEN, KuanHsing. Stuart Hall: critical dialogues in cultural studies. Routledge: London; New York, 1996.

LAFONT, Cristina. The linguistic turn in hermeneutic philosophy. Cambridge, Massachusetts: The MIT Press, 1999.

LÓTMAN, I. As três funções do texto. In: LÓTMAN, I. Por uma teoria semiótica da cultura. Belo Horizonte: UFMG, 2007.

LÓTMAN, I. La semiosfera I: semiótica de la cultura e del texto. Madrid: Ediciones Cátedra, 1996.

LÓTMAN, I. La semiótica de la cultura y el concepto de texto. Revista del Centro de Ciencias del Lenguaje, Puebla, n. 9, p. 15-20, 1993.

LÓTMAN, I. La semiótica de la cultura y el concepto de texto. In: LÓTMAN, I. La semiosfera I: semiótica de la cultura e del texto. Madrid: Ediciones Cátedra, 1996. p. 7782.

LÓTMAN, I. Universe of the mind: a semiotic theory of culture. Bloomington; Indianapolis: Indiana University Press, 1990.

LOTMAN, Iuri. La semiosfera III. semiótica das las artes y de la cultura. Valencia: Frónesis, 2000. 
MACHADO, Irene. Escola de semiótica. A experiência Tártu-Moscou para o estudo da cultura. São Paulo: Fapesp; Ateliê, 2003.

MAINGUENEAU, D. Peut-on assigner des limites à l'analyse du discours ? In: Modèles linguistiques [online], n. 40, 2017. Disponível em:

<https://journals.openedition.org/ml/1409\#tocto1n1>. Acesso em: 11 jul. 2018.

MAINGUENEAU, D. L'analyse du discours. Introduction aux lectures de l'archive. Paris: Hachette, 1991.

MAZIÈRE, Francine. A análise do discurso: história e práticas. São Paulo: Parábola Editorial, 2007.

NOGUEIRA, Paulo A. de Souza. Prefácio. In: NOGUEIRA, Paulo Augusto de Souza (Org.). Religião e linguagem. Abordagens teóricas interdisciplinares. São Paulo: Paulus, 2015.

NOGUEIRA, Paulo A. de Souza. Religião e linguagem: proposta de articulação de um campo complexo. Horizonte, Belo Horizonte, n. 42, p. 240-261, 2016.

NOGUEIRA, Paulo A. de Souza. Traduções do intraduzível: a semiótica da cultura e o estudo de textos religiosos nas bordas da semiosfera. Estudos de Religião, São Bernardo do Campo, n. 29, p. 102-123, 2015.

ORLANDI, Eni P. A linguagem e seu funcionamento: as formas do discurso. 4. ed. Campinas: Pontes, 1996.

ORLANDI, Eni P. Análise de discurso. Princípios e procedimentos. Campinas: Pontes, 1999.

PAULINO, G.; WALTY, I.; CURRY, M. Z. Intertextualidades. Belo Horizonte: Lê, 1995.

PÊCHEUX, Micheal. O discurso. Estrutura ou acontecimento. 5. ed. Campinas: Pontes Editores, 2008.

PÊCHEUX, Michel. Análise automática do discurso (AAD-1969). Cadernos de Estudos Linguísticos, Campinas, n. 19, p. 7-24, 1990.

PÊCHEUX, Michel. Semântica e discurso. Campinas: Pontes, 1988.

RICOEUR, Paul. A memória, a história, o esquecimento. Campinas: Editora da Unicamp, 2007.

SANT'ANNA, Marco D. Os gêneros do discurso. In: UNIVERSIDADE ESTADUAL PAULISTA. Caderno de formação: formação de professores didática geral. São Paulo: Cultura Acadêmica, 2011. p. 68-76. v. 11.

SANTOS, M. S. dos. Memória coletiva e teoria social. São Paulo: Annablume, 2003.

ZABATIERO, Júlio. Manual de exegese. São Paulo: Hagnos, 2007. 